\title{
Socio-Economic Status as Determinants of Students' Performance in English Language in Secondary Schools in Tanzania
}

\author{
Gilman Jackson Nyamubi \\ Department of Education, University of Iringa, Iringa, Tanzania
}

Email address:

gilmubi@yahoo.com

To cite this article:

Gilman Jackson Nyamubi. Socio-Economic Status as Determinants of Students' Performance in English Language in Secondary Schools in Tanzania. Education Journal. Vol. 8, No. 3, 2019, pp. 110-119. doi: 10.11648/j.edu.20190803.14

Received: February 13, 2019; Accepted: May 10, 2019; Published: May 31, 2019

\begin{abstract}
This paper examined how parents' socio-economic status determined students' performance in English language in Tanzania secondary schools. Two research questions and two research objectives guided the study. The study was conducted in two randomly selected Regions in Tanzania Mainland. It employed a cross-sectional survey design to collect data from 350 students in sixteen secondary schools. Data was collected through a questionnaire and achievement tests and was analysed using both descriptive and inferential statistics to get frequencies, means, percentages, as well as Pearson's correlation and regression coefficients. It was found that students in Tanzania secondary schools had varying backgrounds in English language, which was determined by the type of primary school they had attended and the class at which they started to learn English language. The regularity of English language usage at home and school enhanced students' performance in English language together with parents' encouragement as well as material and moral support. It is recommended that parents' socio-economic status should not inhibit learners' exposure to English language learning. Also, parents, schools and government should protract English language teaching and learning through providing current textbooks as well as providing a favourable environment to learn and use English.
\end{abstract}

Keywords: Socio-Economic Status, English Language Learning, Secondary School Students, Tanzania

\section{Introduction}

English is an important language in individual learner's success in the globalizing world [1]. In Tanzania, the language has the wider usage as the medium of communication. It is the medium of instruction in secondary schools and the tertiary level. In this way, English is very vital in learning, thus, it paves the way to students' performance in all subjects taught through this medium.

This academic demand makes English language learning significant, especially in developing students' procedural knowledge and conventions of the language [2]. It is believed that knowledge of English is urgent to make learners progress in life and work because it provides them with higher social status and job opportunities [1].

According to Nyamubi [3], the zeal to learn English has opened venues to young learners of the language hence, many countries including Tanzania, have began to introduce
English at earlier grade levels in their curricular. This may be supported by the fact that in Tanzania today there are parents who opt to send their children in English Medium Primary Schools (EMPS). This is evinced in the multiplicity of English Medium Primary Schools, which however, attract learners whose parents and guardians belong to the higher cluster socially and economically [4].

Education is envisaged in terms of social class, one is education for a less affluent class, another for middle socioeconomic status of society and the final for an upper class [56]. Arguably, the type of education that one gets or receives depends on the wealth and social position of parents. In the same vein, highly educated individuals see the importance of their children to acquire better education, which in their opinion, is offered in private secondary schools [7].

In this regard, an important role that socio-economic status plays in learners' academic achievement cannot be over emphasized [8]. Learning English could also be linked to the 
way learners are exposed to the home and school learning environment. Kormos and Kiddle [9] link students' poor performance in English to their family background, especially regarding parents' education status and income.

\subsection{The Problem}

Students' socio-economic characteristics and their background in English language learning make an important factor in their learning outcomes in the subject. It is predicted that learners are particularly influenced by their parental and family behaviour and attitudes [1]. Parents and family members encourage and support students to learn, thus contributing to students' educational upbringing, including learning English.

The fact that parents' socio-economic status may contribute to students' performance in English language needs to be addressed because education promotes among individuals and community in general, behaviours and attitude changes. It is a means to meet labour needs and for enabling an individual to respond to dynamics of the changing world, especially in the realm of socio-economic and technological advancement. This study focused on how students' background in English as well as their parents' social-economic status determine learners' performance in English language at the secondary school level.

\subsection{Purpose of the Study}

The purpose of the study was to investigate the contribution of students' background in English language and their parents' socio-economic status on their performance in English language. Specifically, the study sought to:

First, find out the contribution of students' English language background on their performance in the subject.

Second, find out the influence of parents' socio-economic status on students' performance in English language.

The following research questions guided the study:

First, to what extent does students' English language background contribute on their performance in the subject?

Second, how does parents' socio-economic status influence students' performance in English language?

\section{Literature Review}

\subsection{Students' Linguistic Background and Language Learning}

Students' success in learning a second or foreign language depends very much on their linguistic gamut, that is, their knowledge of the target language they have that will smooth the progress of their effective learning of the language. Empirical studies show that second or foreign language learning requires a great deal of exposure and practice [1012]. Thus, students' language characteristics such as their pre-school knowledge of the language, the time they were first exposed to the language, the languages they use more frequently and the target language practice both at school and home, seem to be very momentous for a foreign or second language learner [13-14].
In Tanzania, students in secondary schools mirror a wide range of linguistic milieu, depending on their exposure to the language. Additionally, majority of secondary school students, particularly those born outside the urban areas, have a language other than Kiswahili and English as their first language [3, 15]. The amount of exposure to English language outside the school as well as parents' use of the language at home demonstrate a significant influence in children's mastery of the language [2]. This creates an environment where children are exposed to a sheer size of vocabulary that could enable them to master the language.

The child is born in a family and grows within the scope and characteristics of his or her home environment, from which he or she acquires the social behaviours and manners acceptable to the home and the immediate community [16]. In this way, the type and amount of knowledge the child gets before going to school depends much on the home and its environment. This home environment is characterized by parental socio- economic status, the location of the home, including the type of neighbours and peers.

Studies also show that students who perform well in English language in schools, in most cases, come from families in which the language is sometimes spoken and who have friends or peers who speak the language $[4,10]$. It is apparent that students' impulsive English language use outside the class is very important as it gives learners opportunities to use the language for communication.

All these reflect the fact that there is a need for learners to be exposed to the language they learn, in this respect English, in terms of practical meaningful use, both at school and home, so as to enhance their learning of the language. Language practices could be very vital for students' language proficiency and performance.

\subsection{Socio-Economic Status and Performance}

Family income is not reported in many national data sources that contain crucial information about child academic outcomes [17]. In Tanzania, what has not been documented is the relationship between socio-economic variables and performance in English language [18]. Lack of such information may be due to lack of skills in this type of analysis among scholars or the hitherto egalitarian ideology which tended to suggest that class differences could not be pronounced in such a country, and if they did, data on parental income could not be available because being rich was perceived as being 'corrupt' or 'capitalist roader'.

The education system in Tanzania promotes the existence of different social groups, those who can afford to pay fees and other related costs to English Medium Primary Schools and academies and those who cannot even afford the little fees charged in government and community-owned secondary schools [4]. Thus, although the freedom for parents to choose among the available kinds of education opportunities for their children exists in the Tanzania education system, in reality, there is no choice for poor parents [4, 19].

In terms of English language learning in secondary schools, 
studies show that individuals in society occupy different socioeconomic status, with a number of roles attached to it, that each status occupier must play in society [20]. Individuals are never equal nor do they have equal opportunities to engage in societal activities to get equal rewards.

Socio-economic status of a family has been defined as the position of a family in the social class [21]. This could be determined by parents' educational level, occupation and income. Other researchers include family size and the style of life as factors that determine socio-economic status in family [7]. To others, the home environment process: work habits of family members, academic guidance presented to children, children's intellectual simulation, language models as well as parents' expectations and aspiration constitute the family socio-economic status [8, 22]. These factors, to a larger extent, influence children's school achievement.

Parental academic support and intellectual simulation in homes are relevant determinants of pupils' achievement at school [23]. This is because many parents who have higher aspirations and expectations on their children, provide a scheme of consistent methods of reviewing what went on in schools, thus nurture a good home-work habit in their children.

There exists a positive relationship between family socioeconomic status and school achievement among learners [8]. To Ariani and Ghafournia [1], socio-economic factors play a major role in learners' school achievement in that the higher the parents' level of education, occupation and income, the higher the learners' level of school achievement. Cedeño, Martínez-Arias, and Bueno, [21] found a consistent positive relationship between fathers' earnings and their children's scores in secondary schools.

As far as language learning is concerned, few studies have registered the findings of the influence of socio-economic status on language performance. In particular, hardly any studies in this area have been done to examine the influence of socio-economic status on English language performance in Tanzania schools. The present study aimed to fill this gap.

\section{Methodology}

This study was conducted in secondary schools in two Regions in Tanzania: Manyara and Ruvuma. The areas were randomly selected from other twenty-five Regions, in Tanzania Mainland. Two Districts in each Region, representing Urban and Rural backgrounds, were selected. From these, sixteen secondary schools, four from each District, were picked for the study.

The selected Districts were: Babati (Urban) and Mbulu (Rural) in Manyara Region as well as Songea (Urban) and Mbinga (Rural) in Ruvuma Region. Schools in the area had varying characteristics in terms of student composition, which were essential aspects that explained students' socioeconomic status in relation to their performance in English language. A stratified random technique was used to select four schools (two public and two private) from among 49 secondary schools in Babati Town Council and other four schools (two public and two private) from 35 secondary schools in Mbulu District.

In Ruvuma Region, the same method was used to select four schools (two public and two private) from among 39 secondary schools in Songea Municipal Council and other four secondary schools (two public and two private), form Mbinga District, which had 58 secondary schools. The selection of these schools was based on two criteria: Location (urban or rural) and type of school ownership (public or private). Endorsement to visit the schools was obtained from relevant authorities and institutions.

The population of this study included secondary school students in the selected Districts. In particular, the target population included Forms One and Three students. Form One and Form Three students were involved in the study because they were not National examinations classes, as it was the case of Form Two and Form Four. In most cases, examination classes are not engaged in such aspects as being research respondents as it was thought it would limit their time to study. It is not advisable to engage Form Four and Form Two students who are already preparing for their examinations because teachers believe that shifting their attention from studies would likely waste their time [24].

The sample comprised 350 students, that is, 186 males and 164 females. Their ages ranged from 12 to 18 years. In the selected schools, all Form One and Form Three students had an equal chance of being involved in the study. All participants agreed to participate in the study. Respondents were selected by randomly picking one stream in each Form in every school that had more than one stream. Since streaming in Tanzania's secondary schools is not based on ability, it was reasoned that, whichever stream was picked, it would provide a fairly representative sample of all students in that level. In schools where there was only one stream, there was no choice but to pick that stream. The students' composition in each stream ranged from 35 to 76 .

Two data collection instruments were used in this study. These were questionnaires and achievement tests. The questionnaire was designed to elicit students' personal data, their English language background as well as their parents' socio-economic status. The achievement tests in both Form One and Form Three were administered to students so as to establish their performance in English. There were two tests; one for Form One and the other for Form Three. They were both curriculum-based as they covered the content as laid down in the respective syllabi. Both tests consisted of three sections, comprehension, composition and structure or grammar. The whole achievement test was marked out of 100. The marking of both tests was based on a marking scheme. The tests were marked by the researcher and two independent teachers of English. The scores obtained in both tests measured students' performance.

The researcher visited each selected school and administered a questionnaire to respondents in person, with the help a key informant in each school. Respondents were assured of confidentiality and anonymity. They were also given guidelines on how to respond. Assistance was provided, as needed, to help in reading and understanding the 
survey items. Questionnaires were distributed to each respondent, and enough time was given to respond to it. Achievement tests were administered to students a day after they had filled in the questionnaire.

As regards validity and reliability of the instruments, the questionnaire was written in English and later translated into Kiswahili with assistance of a person fluent in both languages. This ensured consistency in the content and meaning. Furthermore, a pilot study was conducted prior administering the survey. This was done to find whether any of the items were ambiguous to ascertain applicability, relevance and usefulness of research tools. The pilot study also served as a means to find the internal consistency or reliability, which was found to be of fairly good quality, with a reliability coefficient of 0.84 . The alpha coefficient was above the cut-off point of 0.70 , indicating good internal consistency as recommended by Sekaran [25]. The main study was done between July-September, 2018.

The data collected from the field was systematically organised to facilitate analysis. It was first coded then were entered and analysed using SPSS for windows (version 21) following IBM guidelines. Cross tabulation was performed to obtain frequencies, means and percentages of students' responses on their background in English as well their parents' socio-economic status. Pearson's correlations were calculated to look at the strength and direction of the relationship between the variables. The test of significance was performed at the probability level of $\mathrm{p}<0.05$. A standard multiple regression analysis was performed to examine the impact of parents' socioeconomic status factors on students' performance in English language, in which the strong predictors were identified.

\section{Results}

The students' socio-economic status was predicted to be related to students' performance in English language. The study explored the extent of students' socio-economic status, as inferred from parents' level of education and occupation, influenced their performance in English language.

Table 1. Respondents' Demographic Information.

\begin{tabular}{lll}
\hline Characteristics & N & Percentage \\
\hline Sex & & \\
Male & 186 & 53.1 \\
Female & 164 & 46.9 \\
Class & & \\
Form One & 192 & 54.9 \\
Form Three & 158 & 45.1 \\
School location & & \\
Urban & 176 & 50.3 \\
Rural & 174 & 49.7 \\
Type of School ownership & & \\
Public & 178 & 50.9 \\
Private & 172 & 49.1 \\
\hline
\end{tabular}

Table 1 shows demographic and school characteristics of study respondents who were 350 in all. There were 186 males (53.1 percent) and 164 females (46.9 percent). In addition, 54.9 percent of students were studying in Form One while 45.1 percent were in Form Three. As regards school location, 50.3 percent of respondents $(\mathrm{N}=176)$ were from secondary schools in the Urban setting and 49.7 percent $(\mathrm{N}=174)$ were from Rural schools. Finally, 49.1 percent of respondents were from private secondary schools while 50.9 percent were from public secondary schools.

\subsection{Language Performance Levels}

The performance of both Forms One and Form Three in achievement tests are given in Tables Two and Three. The results are presented separately according to the classes in all schools. They show how students performed in the three sections: comprehension, structure and composition.

Table 2. Form One Performance by Test Sections and Gender.

\begin{tabular}{|c|c|c|c|c|c|c|c|}
\hline \multirow{3}{*}{ Section } & \multirow{3}{*}{ Maximum Score } & \multicolumn{4}{|c|}{ PERFORMANCE LEVEL } & \multirow{2}{*}{\multicolumn{2}{|c|}{ Total $(\mathrm{N}=192)$}} \\
\hline & & \multicolumn{2}{|c|}{ Male $(N=106)$} & \multicolumn{2}{|c|}{ Female $(\mathrm{N}=86)$} & & \\
\hline & & Mean & SD & Mean & SD & Mean & SD \\
\hline Comprehension & 30 & 14.87 & 3.73 & 13.63 & 3.65 & 14.25 & 3.28 \\
\hline Structure & 35 & 22.64 & 5.16 & 21.94 & 5.27 & 22.29 & 5.91 \\
\hline Composition & 35 & 14.36 & 6.32 & 11.56 & 5.13 & 12.86 & 5.74 \\
\hline Whole Test & 100 & 51.87 & 11.65 & 47.13 & 10.82 & 49.40 & 12.66 \\
\hline
\end{tabular}

Results show that in Form One, the comprehension section had an average score of 14.25 out of 30 . Performance in structure was on the whole; better than other sections, with the mean score being 22.29, male students making a mean score of 22.64 while the females' score was 21.94. Results in the composition section had the lowest mean score of 12.86, with male students attaining a mean score of 14.36 doing better than female students whose mean score was 11.56 . The average score of the whole test was 49.40 out of 100 , with males having a mean score of 51.87 percent and females 47.13 percent.

Table 3. Form Three Performance by Test Sections and Gender.

\begin{tabular}{|c|c|c|c|c|c|c|c|}
\hline \multicolumn{2}{|l|}{ TEST } & \multicolumn{6}{|c|}{ PERFORMANCE LEVEL } \\
\hline \multirow{2}{*}{ Section } & \multirow{2}{*}{$\begin{array}{l}\text { Maximum } \\
\text { score }\end{array}$} & \multicolumn{2}{|c|}{ Males $(\mathbf{N}=84)$} & \multicolumn{2}{|c|}{ Females $(N=74)$} & \multicolumn{2}{|c|}{ Total $(\mathrm{N}=158)$} \\
\hline & & Mean & SD & Mean & SD & Mean & SD \\
\hline Comprehension & 30 & 17.21 & 5.39 & 14.37 & 6.01 & 15.79 & 6.91 \\
\hline Structure & 35 & 22.24 & 5.48 & 19.36 & 4.69 & 20.80 & 5.87 \\
\hline Composition & 35 & 18.78 & 5.17 & 17.22 & 4.72 & 18.00 & 4.64 \\
\hline Whole Test & 100 & 58.23 & 11.43 & 50.95 & 10.82 & 54.59 & 10.23 \\
\hline
\end{tabular}


Table 3 shows that in Form Three, students' score in the composition section was the lowest compared to other sections (a mean score of 18.00) with the malestudents scoring an average of 18.78 , and females mean score was 17.22. The performance in structure was, as in Form One, better than in other sections, with the mean score of 20.80 , with males having 22.24 and females 19.36. The comprehension section had mean scores of 17.21 for males and 14.37 for females. The mean score of the whole test was 54.59, with males making 58.23 and females 50.95 .

\subsection{Students' Linguistic Background and Performance}

Data regarding secondary school students' English language background was collected to check whether this contributed to their performance in English at their current class level. Three sets of data were sought: First, the type of primary school attended, second, the class at which students started learning English and third, students' use of English at home and school.

Table 4. Type of primary school attended and class when students started learning English.

\begin{tabular}{|c|c|c|c|c|c|c|c|c|c|c|c|}
\hline \multirow{2}{*}{ SN } & \multirow{2}{*}{ STATEMENT } & \multicolumn{2}{|c|}{ Kindergarten } & \multicolumn{2}{|c|}{ Standard I } & \multicolumn{2}{|c|}{ Standard III } & \multicolumn{2}{|c|}{ Swahili Medium } & \multicolumn{2}{|c|}{ English Medium } \\
\hline & & $\mathbf{N}$ & $\%$ & $\mathbf{N}$ & $\%$ & $\mathbf{N}$ & $\%$ & $\mathbf{N}$ & $\%$ & $\mathbf{N}$ & $\%$ \\
\hline 1 & Public secondary school $(\mathrm{N}=178)$ & 37 & 20.8 & 0 & 0 & 141 & 79.2 & 79.2 & 37 & 37 & 20.8 \\
\hline 2 & Private secondary school $(\mathrm{N}=172)$ & 70 & 40.7 & 26 & 15.1 & 76 & 44.2 & 44.2 & 96 & 96 & 55.8 \\
\hline
\end{tabular}

The data indicate that, of all respondents $(\mathrm{N}=350)$, only 38 percent $(\mathrm{N}=133)$, attended English medium primary school, while the majority of them 62 percent $(\mathrm{N}=217)$ had their primary education through the Kiswahili medium of instruction. Education in almost all public primary schools Tanzania is provided through the medium of Kiswahili.

As for the class when they started learning English language, the majority of students or 62 percent $(\mathrm{N}=217)$, showed that they started learning English language while they were in Standard Three. Few of the respondents, however, indicated that they had started learning English language in earlier classes. These were: Kindergarten 30.5 percent $(\mathrm{N}=107)$ and Standard One 7.5 percent $(\mathrm{N}=26)$.

Table 5. Students' rating of their use of English at home and school.

\begin{tabular}{|c|c|c|c|c|c|c|c|c|c|}
\hline \multirow{2}{*}{ SN } & \multirow{2}{*}{ STATEMENT } & \multicolumn{2}{|c|}{ Very often } & \multicolumn{2}{|c|}{ Often } & \multicolumn{2}{|c|}{ Rarely } & \multicolumn{2}{|c|}{ Never } \\
\hline & & $\mathbf{N}$ & $\%$ & $\mathbf{N}$ & $\%$ & $\mathbf{N}$ & $\%$ & $\mathbf{N}$ & $\%$ \\
\hline 1 & English language use at home & 14 & 4.0 & 78 & 22.3 & 142 & 40.6 & 116 & 33.1 \\
\hline 2 & English language use at school & 212 & 60.6 & 126 & 36.0 & 12 & 3.4 & 0 & 0 \\
\hline
\end{tabular}

When asked how often students used English language for communication, both at home and school, respondents showed that they used the language most often at school than when they were at home. Table 5 shows that the majority of students $(\mathrm{N}=142)$ admitted that they rarely used English language at home, and 33.1percent disclosed that they did not use it at all. However, 26.3 percent indicated that they used English language at home when communicating with parents, friends and relatives.

At school, the situation is somehow different because the frequency of English language use was reported to be much higher. Students, 96.6 percent, used the language at school for communication. The rest of the respondents or 3.4 percent admitted that they rarely used the language at school. It was reported that at school, students often had contacts with their teachers as well as amongst themselves through this medium.

The test scores were used as the dependent variable and were correlated with students' background in English language factors as independent variables. It was expected that these aspects would determine their performance in English language. Results indicated that there was evidence to support this assertion. Table 6 summarizes the results.

Table 6. Correlation between students' background in English language and Test Scores.

\begin{tabular}{lllll}
\hline & Performance & Type of primary school attended & Class started learning English & English use at home \\
\hline Type of p/school attended & $0.410^{* *}$ & & & \\
Class started learning English & $0.465^{* *}$ & 0.242 & & \\
English language use at home & $0.284^{* *}$ & 0.114 & 0.211 & 0.021 \\
English language use at school & $0.761^{* *}$ & $0.321^{* *}$ & 0.233 & \\
\hline
\end{tabular}

Key: ** Correlation is significant at 0.01 level.

The whole test produced positive and significant coefficients when it was correlated with the four socioeconomic variables. These were class at which students started to learn English 0.465 and type of primary school attended 0.410. Language use at school yielded the higher correlation coefficient all other students' background in
English language indicators (0.761). The English language use at home had the lowest correlation coefficient of 0.284 .

\subsection{Social Economic Status and Performance}

Students' parents who were professionals were categorized as upper category; students with parents with semi- 
professionals fell into the middle category; while students whose parents were from non-professional or manual labour backgrounds were considered lower category status. In terms of the highest education level reached by parents, the six categories $(\mathrm{PhD}$, Post-Graduation, Graduation, Secondary school education, primary education and absence of formal education) were used to measure the highest educational level reached by students' Fathers and Mothers.

Thus, students whose parents had post-secondary school education, that is, Diploma and University education were considered as high category. Students, whose parents had secondary education, ordinary level or advanced level, fell into the middle category, while students whose parents had only primary education or less, were considered lower category.

Table 7. Students' Socio-Economic Background.

\begin{tabular}{|c|c|c|c|c|c|c|c|}
\hline & \multicolumn{2}{|c|}{ Lower } & \multicolumn{2}{|c|}{ Middle } & \multicolumn{2}{|c|}{ Upper } & \multirow{2}{*}{ MEAN } \\
\hline & $N$ & $\%$ & $N$ & $\%$ & $N$ & $\%$ & \\
\hline Father's Education & 100 & 28.6 & 200 & 57.1 & 50 & 14.3 & 0.62 \\
\hline Mother's Education & 82 & 23.4 & 214 & 61.2 & 54 & 15.4 & 0.64 \\
\hline Father's Occupation & 120 & 34.3 & 172 & 49.1 & 58 & 16.6 & 0.61 \\
\hline Mother's occupation & 106 & 30.3 & 173 & 49.4 & 71 & 20.3 & 0.63 \\
\hline
\end{tabular}

Data showed that 14.3 percent of respondents had their Fathers' education in the higher education category; 28.6 percent were in the lower category; and the majority of them, 57.1 percent had their Fathers' education in the middle category. In all, Fathers' education had a Mean score of 0.62. Regarding their Mother's education $(\mathrm{M}=0.64)$, again, majority of students (61.2 percent), had Mothers whose education level that lies in the middle category, while only few (15.4 percent) were in the upper category and 23.4 percent were in the lower category.

As regards students' Father's occupation $(\mathrm{M}=0.61)$ and
Mothers' occupation ( $\mathrm{M}=0.63)$, data show that majority of students had parents whose occupational status lies in the middle category (49.1 and 49.4, respectively). In the upper category, facts show that Fathers occupation level constituted 16.6 percent, and students' Mothers had 20.3 percent. In the lower category almost One Third of both parents were in this class.

Students' socio-economic status was also measured through their perceived parental support and encouragement to learn English language. Data on this is summarized in Table 8.

Table 8. Students' perceived parental encouragement and support to learn English.

\begin{tabular}{|c|c|c|c|}
\hline Scale item & Statement & Mean & Std. Dev \\
\hline PE 1 & My parents encourage me to practice my English as much as possible. & 3.51 & 0.626 \\
\hline PE 2 & My parents have stressed the importance English & 3.58 & 0.613 \\
\hline PE 3 & My parents think I should devote more time to studying English. & 3.25 & 0.712 \\
\hline PE 4 & My parents feel that it is very important for me to learn English. & 2.69 & 0.635 \\
\hline PE 5 & My parents feel that I should continue studying English all my life. & 2.58 & 0.465 \\
\hline PE 6 & My parents are very interested in everything I do in my English classes. & 2.28 & 0.581 \\
\hline Parental encouragement & & 3.00 & \\
\hline PS1 & My parents give me study materials to support my English learning. & 3.57 & 0.614 \\
\hline PS 2 & Young people in my area like learning English language. & 2.76 & 0.613 \\
\hline PS 3 & I feel comfortable in my school because I get basic services. & 3.38 & 0.601 \\
\hline PS 4 & There are enough English books. & 2.84 & 0.711 \\
\hline PS 5 & My parents follow up my school homework. & 3.46 & 0.714 \\
\hline PS 6 & I am provided with school needs. & 2.78 & 0.652 \\
\hline
\end{tabular}

Parental encouragement (with a mean score of 3.00), had seven items. Students revealed that their parents always stressed to them regarding the importance of learning English, they therefore encouraged their children to practice using English as much as possible. It follows that most parents thought that their children needed to devote more time studying English; hence parents tried as much as they could to help their children learn English. Most parents felt that English was so important that their children should continue learning the language all their academic and career life. In this way, most parents were very interested in all what their children did in their English classes.

Regarding parental support, students indicated that parents provided them with school needs and educational material, such as textbooks to support their children's English language learning. Students therefore felt comfortable to learn English because most parents followed up their school homework and a handful of young people around them, liked learning English.

Students' score in a test was considered a dependent variable, while parents' socio-economic status (Father's education, Mother's education, Father's occupation, Mother's occupation, parental encouragement and parental support) were dependent variables. To identify the strongest predictor of students' performance in English language among the six parents' socio-economic status factors, a standard multiple 
regression analysis was performed. Results presented in

74.48, $\mathrm{p}<0.001), \mathrm{R}=0.506$.

Table 9 shows that the regression model was significant $(\mathrm{F}=$

Table 9. Regression outputs on parents' SES and students' performance in English.

\begin{tabular}{|c|c|c|c|c|c|}
\hline & \multicolumn{2}{|c|}{ Unstandardised coefficients } & \multirow{2}{*}{$\begin{array}{l}\text { Standardised coefficients } \\
\text { Beta }\end{array}$} & \multirow{2}{*}{$t$} & \multirow{2}{*}{ Sig } \\
\hline & $B$ & Std. error & & & \\
\hline Constant & 0.678 & 0.453 & & 0.991 & 0.008 \\
\hline Father’s education & 0.543 & 0.263 & 0.06 & 0.742 & 0.067 \\
\hline Mother's education & 0.602 & 0.116 & 0.12 & 0.461 & $0.009^{* *}$ \\
\hline Father's occupation & 0.347 & 0.316 & 0.04 & 0.236 & 0.075 \\
\hline Mother's occupation & 0.581 & 0.218 & 0.09 & 0.122 & 0.063 \\
\hline Parental encouragement & 0.614 & 0.145 & 0.15 & 0.419 & $0.000 * *$ \\
\hline Parental support & 0.627 & 0.147 & 0.18 & 0.541 & $0.000 * *$ \\
\hline
\end{tabular}

Key:

$\mathrm{B}=$ Unstandardised Beta coefficient,

Beta $=$ Standardised Beta coefficient,

Std. Error= Standardised error of Beta.

All six parents' socio-economic status factors are predictors of students' performance in English. The adjusted $\mathrm{R}^{2}$ value of 0.64 indicates that all predictor variables explain $64 \%$ of variation students' performance in English in secondary schools in Tanzania. This implies that 36\% variation in students' performance in English is explained by other factors.

When these socio-economic status factors were separately considered, it was found that parental support was the strongest predictor of students' performance in English as a school subject (Beta $=0.627, \mathrm{p}=0.000)$, followed by parental encouragement $(B e t a=0.614, p=0.000)$, Mother's education (Beta $=0.602, \mathrm{p}=0.009)$, Mother's occupation (Beta $=0.581$, $\mathrm{p}=0.025)$, Father's education $(B e t a=0.543, \mathrm{p}=0.017)$ and lastly Father's occupation (Beta $=0.347, \mathrm{p}=0.013$ ).

In addition, data indicates that three variables in the model had slight positive affects students' performance in English language. These are: Father's occupation $(B=0.04)$, Father's education $(\mathrm{B}=0.06)$, and Mother's occupation $(\mathrm{B}=0.09)$. However, this slight effect was not significant. Parental support had a significant and positive effect on students' performance in English language ( $\mathrm{B}=0.18)$, as it was the case of parental encouragement $(B=0.15)$ and Mother's education $(\mathrm{B}=0.12)$.

\section{Discussion}

\subsection{The Significance of Background Variables in English Language Learning}

Students in Tanzania secondary schools have different know-how in terms of their involvement in learning English language when they enter their first year of school. This depends very much on the way they learned the language at lower school levels. Anderson [26] notes that language reflects social processes such as teaching techniques, remedial courses, specialized tests as well as changing situations in which English language is taught, learnt and used.
In terms of the class in which students started to learn English language, the role of competency in the language acquired prior standard three had very little influence on students' performance in the subject at the secondary school level. Most students had very little knowledge of English language when they joined secondary schools. The findings are in alignment with those by Batibo ([27] and Qorro [28] that students in Tanzania public primary schools hardly complete their education with sufficient knowledge of English language.

Thus, poor English language foundation is one of the major causes of students' poor performance in the subject at the secondary school level. As noted by Upor [29], learners at the same level are at different stages of linguistic development due to variation of learning environments in schools. In this way, secondary school students' relative proficiency level does not show significant differences between beginners and final year students [30].

Regarding English language use at home, most students hardly used English language in the home milieu, which limited their means to advance their grasp of the language. Upor [29] is of the opinion that second or foreign language learning requires students' exposure and practice of the language they learn, in that extended use of verbal morphology results in learners' English language increase proficiency. As argued by Nyamubi [13], students' limited exposure to English language in the home environment may greatly affect their knowledge of the language as well as their performance in the subject.

As regards English language use at school, students communicated through English most frequently for communication. Students are more exposed to English language when they are at school than when they are at home. Complementing this, Upor [30], notes that the only source of English learning is the classroom. In addition, Upor [29] affirms that learners perform better in English language when their learning, especially the acquisition of tense-aspect morphology, is strengthened through regular practice. In this 
case, learners' frequent use of the language plays an important part in sustaining the language skills and knowledge being taught.

The findings of the present study based on the fact that English is learnt at school than other contexts, supports Anderson's [26] argument that English is used most often at school, where it is taught in a punitive way, that is, teachers use various punishments to enforce the speaking of English outside the classroom. It was further revealed that students' better performance in English language is facilitated by their root in the situations under which they learned their English [4]. The students' language background factors are more significant where there are greater differentiations in social classes.

\subsection{Socio-Economic Status and School Performance}

In terms of students' socio-economic status, parents' education and occupation are strongly related to students' performance in English language. Coming from low social class families where academic needs such as availability of learning materials are often not met fully results in poor performance in English language. Duncan and Brooks Gunn [17] found that poverty limits family's ability to provide a comfortable and protective home environment as children from poor families live in poor houses where they are not provided with education related equipment such as table, chair or books. This, arguably, limits learners' learning and performance in English language.

Consistent to this, Ariani and Ghafournia [1] observed that socio-economic backgrounds contributed to the students' academic performance in school subjects, while Lupeja and Gubo [31] found that failing students believed that having uneducated parents affected their school performance. Although these studies were about the general performance in all school subjects at both primary and secondary school levels, their findings seem to align with what the present study found in relation to students' performance in English language.

It was found in this study that parents' educational level yielded moderate correlation coefficients with students' performance in English language. Thus, having educated parents facilitated students' performance in the subject. This is in support of Ariani and Ghafournia [1] study that parents' socio-economic characteristics mark an important factor in learners' English language learning outcomes. Thus, parents' education, more than parents' occupation, influenced, to a great extent, students' performance in English language.

Students indicated one other home or family background factor, that is, materials and moral support from parents and relatives, as very vital in their performance in English language. They were motivated to learn the language when they were supplied with adequate learning materials, because this enabled them to learn more about the language. This notion is supported Dev and Qiqieh [2] who found that children develop intellectual and creative skills as a result of the kind of environment at home.

Similar to this, Kakumbi, Samuel, and Mulendema [7] argue that exposure to educational resources and recreational facilities helps learners to gain and retain what they learn. Parents' use of their social economic ability on the child's academic orientation, rather than just their status, is what counts in the child's learning environment, hence better performance in English. It is argued that children whose parents are economically resourceful tend to associate educational materials with their children's academic achievement [32] because these parents see these materials as agents for promoting their children's interest in learning. Students who do better come from better-off families that have more contact with English in a variety of circumstances [26].

In this regard, parents with a higher socio-economic status prepare their children for school more adequately than those from the lower cluster [7, 20, 33]. As a result, the former group stands a better position to succeed in their studies. In this way, parents in the higher socio-economic status cluster are able to pay for their children's education in private and expensive secondary schools with qualified teachers [4]. In these schools, just like homes, learners have an avenue to use English.

Another socio-economic factor that facilitates students' English language learning is parental involvement. Parents encourage school success among learners in a way that provides structures that are conducive for learning [12, 32]. The present study revealed, like Ogunshola and Adewale [34] observation, that parents' education level especially that of the mother, is a predictor of children's performance in English language because it equips parents with the ability to provide a supportive learning environment.

Parents effectively support their children's education when they believe that their role of helping in educating their children is vital. As argued by Amponsah, Milledzi, Ampofo and Gyambrah [35], students whose parents are educated, communicate with their children school work, activities and information being taught at school. Such parents influence endorsement to introduce their children to learn English at earlier ages [4]. They also make decisions such as how much time to spend with their children as well as how much income to give for their children's education [36].

Students' performance in English as a school subject relies on parents' involvement in their academic activities to attain higher level quality in academic success [32]. It is therefore very vital that parents' socio-economic status as an influencing factor of students' learning be addressed when planning education for sustainable development.

\section{Conclusions and Recommendations}

Based on findings, it is concluded that students in Tanzanian secondary schools have varying backgrounds in English language, especially depending on the type of primary school they had attended, and the class at which they started to learn English language. It is apparent that these variables are important factors that determine students' performance in English at the secondary school level. The 
regularity of English language usage, especially at school, produced high correlations with students' performance in the subject.

Students perform better in English when they receive material and moral support as well as encouragement from their parents. Similarly, parents' occupation and level of education are important correlates of language competency. Students' sustainability in learning English is likely to be stable, given the local job market and international communication needs, as much of it is done through that medium.

It is recommended that first, parents' socio-economic status, high or low, should not hold back learners from being exposed to the English language learning environment both at home and school. In this, there is a need for schools and parents to team up to facilitate realization of learners' English language learning aspiration.

Second, there is a need to have schools' awareness regarding students' English language backgrounds as well as their socio-economic status differences, so that teachers would help learners' English language learning. This will help in improving learners' English proficiency.

Third, parents should support their children in termsof English language recourses to hearten their English learning. Fourth, the government needs to sustain English language teaching and learning by endowing schools with current textbooks in helping students' English performance.

\section{References}

[1] Ariani, M. G \& Ghafournia, N. (2016). The relationship between socio-economic status, general language learning outcome, and beliefs about language learning. International Education Studies, 9 (2), 89-98.

[2] Dev, S \& Qiqieh, S. (2016). The Relationship between English language proficiency, academic achievement and selfesteem of non-native-English-speaking students, International Education Studies, 9 (5), 147-155.

[3] Nyamubi, G. J. (2016). Students' attitudes and English language performance in secondary schools in Tanzania. International Journal of Learning, Teaching and Educational Research, 15 (2), 117-133.

[4] Rugemalira, J. M. (2006). Theoretical and practical challenges in Tanzanian English Medium Primary Schools. Papers in Education and Development, 26, 89-115.

[5] Babikkoi, M. A, \& Abdul-Razak, N. Z. (2014). Implications of parents' Socio-economic status in the choice of English language learning strategies among Nigeria's secondary school students. English Language Teaching, 7(8).

[6] Juan, A \& Visser, M. (2017). Home and school environmental determinants of science achievement of South African students. South African Journal of Education, 37 (1), 1-10.

[7] Kakumbi, Z, Samuel, E. B. \&Mulendema, P. J. (2016). Pupil home background characteristics and academic performance in senior secondary schools: A case study of selected secondary schools in Kitwe District, Zambia. Journal of Education and Practice, 7 (22) 19-25.
[8] Owolewa O, O \& Olagundoye, O. C. (2017). Socio-economic status as determinants of students' achievements in English language. Journal of Education and Practice, 8 (21), 110-112.

[9] Kormos, J \& Kiddle, T. (2013). The role of socio-economic factors in motivation to learn English as a foreign language: The case of Chile. System, 41, 399-412.

[10] Hol, D \& Yavuz, A. (2017). The Role of socio-economic status on the EFL learners' attributions on success and failure. International Journal of Liberal Arts and Social Science, 5 (9), 29-38.

[11] Komba, S. C, Kafanabo, E. J, Njabili, A. F\& Kira, E. S. (2012). Comparison between students' academic performance and their abilities in written English language skills: A Tanzanian perspective. International Journal of Development and Sustainability, 1, (2) 305-325.

[12] Atli, I. \& Özal, D. (2017). Does English Medium Instruction (EMI) make a difference on student motivation? Journal of Language Research, 1(1), 25-36.

[13] Nyamubi, G. J. (2003). The influence of motivation on secondary school students' performance in English language. HURIA Journal of the Open University of Tanzania, 5, 89-110.

[14] Gayton, A. (2010). Socio-economic status and languagelearning motivation: To what extent does the former influence the latter? Scottish Languages Review, 22, 17-28.

[15] Mapunda, G. (2013). Ngoni people's attitudes towards the use of Kingoni in beginner classes. Journal of Linguistics and Language Education, 7 (1), 74-92.

[16] Schulze, S \& Lemmer, E. (2017). Family experiences, the motivation for science learning and science achievement of different learner groups. South African Journal of Education, $37(1), 1-9$.

[17] Duncan, G. J. and Brooks - Gunn, J. (2000). Family, poverty, welfare, reforms and child development. Child Development, 71 (1), 188-196.

[18] Omari, I. M. (1994). Review of Critical Issues in Education in Tanzania. Dar es Salaam: World Bank.

[19] Ouma, D. H, Zuo-Ting, Z \& Pesha, J. C. (2017). Analysis of the socio-economic factors that contribute to children school dropout in artisanal small-scale gold mining communities of Tanzania. Journal of Education and Practice, 8 (14), 71-78.

[20] Vellymalay, S. (2012). Parental involvement at home: Analyzing the influence of parents' Socio-economic status. Studies in Sociology of Science, 3(1), 1-6.

[21] Cedeño, L. F, Martínez-Arias, R \& Bueno, J. A. (2016). Implications of Socio-economic status on academic competence: A perspective for teachers. International Education Studies, 9 (4), 257-267.

[22] Eneji, C. V. O, Ubom-Bassey A. E, Eneji, J. E. O, Obogo, G. O \&Dunnamah, A. Y. (2013). Influence of family types and parent's socio-economic status on school dropout among female students in the Old Ogojazone of Cross River, Nigeria. Global Advanced Research Journal of Arts and Humanities, 2(1), 7-13.

[23] Omoegun, M. (2007). Effect of parental socio-economic status on parental care and social adjustment in the UBE programme in Lagos State: Implications for counselling. International Journal of Educational Research, 3(1), 81-87. 
[24] Mapunda, G. (2018). An investigation of performance in national English language examinations in Tanzania: A curriculum processes perspective. Journal of Education, Humanities and Sciences, 7 (1), 45-58.

[25] Sekaran, U. (2005). Research methods for business: A skillbuilding approach $\left(4^{\text {th }} \mathrm{ed}\right.$.). New York: John Wiley.

[26] Anderson, R. W. (2013). The language factor in educational performance at university level. Journal of Linguistics and Language Education, 7 (1), 106-131.

[27] Batibo, H. M. (1990). English language teaching and learning in Tanzanian primary schools. In C. M. Rubagumya (ed). Language in Education in Africa: A Tanzanian perspective, (111-112). Philadelphia: Multilingual Matters.

[28] Qorro, M. (2012). Implications of investigating ELT at an early age in Tanzanian primary schools: A response to the proposed language in education policy. In M. Qorro, Z. Desai and B. Brock-Utne (eds). Language of Instruction: A key in understanding what the teacher is saying, (117-132). Dar es Salaam: KAD Associates.

[29] Upor, R. A. (2014). What it makes little or no difference: The influence of instruction on the acquisition of the English past tense among Tanzania learners. Papers in Education and Development, 32, 95-120.

[30] Upor, R. A. (2013). A review of methodological choices in researches on the development of tense-aspect in narrative of EFL learners: Reflections for Tanzania. Journal of Linguistics and Language Education, 7 (1), 64-73.
[31] Lupeja, T. L \& Gubo, Q. (2016). Secondary education attainment and social economic transformation in rural Tanzania: Observations from livelihood strategies of primary and secondary education graduates in Mvomero District. Journal of Education and Practice, 7 (32), 144-150.

[32] Hamid, M. O. (2011). Socio-economic characteristics and English language achievement in Rural Bangladesh. Bangladesh e-Journal of Sociology, 8(2), 31-51.

[33] Pillay, J. (2017). The relationship between housing and children's literacy achievement: Implications for supporting vulnerable children. South African Journal of Education, 37 (2), 1-10.

[34] Ogunshola, F \& Adewale, A. M. (2012). The effects of parental Socio-economic status on academic performance of students in selected schools in Kwara State Nigeria. International Journal ofAcademic Research in Business and Social Sciences, 2(7).

[35] Amponsah, M. O, Milledzi, E. Y, Ampofo, E. T \& Gyambrah, M. (2018). Relationship between parental involvement and academic performance of senior high school students: The case of Ashanti Mampong Municipality of Ghana. American Journal of Educational Research, (1), 1-8.

[36] Khair, A. U. (2014). The correlation of parenting and socioeconomic status towards English learning readiness of children. Ethical Lingua, 1 (2), 74-85. 